Historia

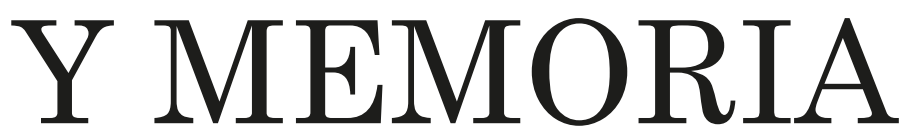

ISSN: 2027-5137

Enero - Junio, Año 2019 - Tunja, Colombia

Violencia política y relatos desde la dimensión subjetiva

https:/doi.org/10.19053/20275137.n18.2019.7356

Martha Cecilia Herrera1

Vladimir Olaya 2

Páginas 49-76

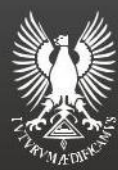




\title{
Violencia política y relatos desde la dimensión subjetiva*
}

\author{
Martha Cecilia Herrera ${ }^{1}$ \\ Vladimir Olaya ${ }^{2}$ \\ Universidad Pedagógica Nacional-Colombia
}

Recepción: 31/10/2017

Evaluación: 20/03/2018

Aprobación: 16/11/2018

Artículo de Investigación e Innovación

doi https:/doi.org/10.19053/20275137.n18.2019.7356

\section{Resumen}

En Colombia se afirma que es tiempo de memoria para aludir al posicionamiento en la agenda pública de los asuntos de violencia política acaecidos en nuestra historia reciente, lo cual ha dado pie al desarrollo de investigaciones académicas y al diseño de políticas públicas tendientes al esclarecimiento de lo acontecido y de sus posibles soluciones. Desde este horizonte el artículo reflexiona sobre la importancia de la literatura biográfica y testimonial y su pertinencia dentro de la investigación histórica para el abordaje de este tipo de

\footnotetext{
* El presente artículo de reflexión es parte de los resultados del proyecto de investigación «Configuración de subjetividades y constitución de memorias sobre la violencia política en América Latina». Financiado por la Universidad Pedagógica Nacional (CIUP). DPG-449-17 (inicio 6 de febrero 2017, finalización 6 de febrero de 2018).

1 Socióloga y Magíster en Historia. Doctora en Filosofía e Historia de la Educación. Profesora Emérita de la Universidad Pedagógica Nacional. Integrante del Grupo de Investigación Educación y Cultura Política. Línea de Investigación Educación y Cultura Política. (1) https://orcid.org/0000-0003-4170-7822. \ malaquita10@gmail. com. Investigadora Senior. Colciencias.

2 Licenciado en Lingüística y literatura y Magíster en Educación. Estudiante del Doctorado Interinstitucional en Educación- Universidad Pedagógica Nacional, Universidad Distrital y Universidad del Valle. Profesor Ocasional y Titular de la Universidad Pedagógica Nacional. Integrante del Grupo de Investigación Educación y Cultura Política. Línea de Investigación Educación y Cultura Política. (D) https:// orcid.org/0000-0002-3935-3271. వ Vlado2380@gmail.com. Investigador Asociado. Colciencias.
} 
problemáticas. Como parte de este propósito se analiza uno de los relatos testimoniales recolectados en una investigación llevada a cabo en torno a la configuración de subjetividades en contextos de violencia política, indicando como este tipo de fuentes al tiempo que habilitan al sujeto corriente como participante de un momento histórico determinado, revelan, a su vez, los estrechos lazos existentes entre individuo y sociedad.

Palabras claves: Violencia política, Conflicto armado, Relatos biográficos, Memoria, Historia reciente.

\title{
Political Violence and Narratives. A Subjective Dimension
}

\begin{abstract}
The time has come for memory. This current phrase in Colombia suggests the positioning of recent political violence issues in the public agenda, which has triggered the development of academic research as well as the design of public policies that aim at the clarification of events related to the armed conflict and their possible solutions. From this horizon, this paper analyzes the importance of biographical and testimonial literature, and its pertinence to historical research on political violence. In order to do so, we analyze one of the testimonial narratives collected in a research project regarding the configuration of subjectivities in contexts of political violence, and indicate how this type of resources both empower the ordinary subject as participant of a given historical moment and reveal the close bond between individual and society.
\end{abstract}

Key Words: Political Violence, Armed Conflict, Biographical Narratives, Memory, Recent History. 


\section{Violence politique et récits: la dimension subjective}

\section{Résumé}

On affirme en Colombie que le temps de la mémoire est arrivé, pour indiquer le positionnement dans l'agenda public des affaires de violence politique de notre histoire récente, ce qui a suscité le développement de recherches académiques et la configuration de politiques publiques dont le but est l'éclaircissement du passé et la recherche de possibles solutions. Situé dans ce contexte précis, l'article réfléchit à propos de l'importance de la littérature biographique et des témoignages et de leur pertinence au sein de la recherche historique pour aborder ce genre de problématique. Afin de mener à bien cette tâche, nous analysons l'un de ces témoignages, collecté dans le cadre d'une recherche à propos de la configuration des subjectivités dans des contextes de violence politique. Nous montrons comment ces sources permettent de transformer des sujets ordinaires en participants d'un moment historique donnée, et comment elles mettent au jour les liens étroits qui lient l'individu et la société.

Mots-clés: Violence politique, Conflit armé, Récits biographiques, Mémoire, Histoire récente.

\section{Introducción}

En el campo de las ciencias sociales, en el que incluimos la educación, los materiales biográficos de distinta índole, dentro de los que se cuentan historias de vida, relatos de vida, testimonios, autobiografías, entre otros registros, revisten interés investigativo en la medida en que dan cuenta del plano de las subjetividades, permitiendo una aproximación, a través de su especificidad, a la tensionalidad dada entre las dimensiones estructurales y las que atañen a los sujetos ${ }^{3}$. Lo que en las últimas décadas se ha conocido como giro cultural o giro subjetivo ha situado en la esfera de la investigación la pertinencia de articular lo estructural y lo

3 Leonor Arfuch, «El espacio teórico de la narrativa: un desafío ético y político». Utopía y praxis latinoamericana, $\mathrm{n}^{\circ} 42$ (2008): 131-140. 
fenomenológico en los análisis que se llevan a cabo en ciencias sociales. En palabras de Pujada:

[...]La recuperación y gran auge del método biográfico en estos últimos veinte años forma parte de la revalorización del actor social (individual y colectivo), no reducible a la condición de dato o variable (o a la condición de representante arquetípico de un grupo), sino caracterizado como sujeto de configuración compleja y como protagonista de las aproximaciones que desde las ciencias sociales se quiere hacer de la realidad social[... $]^{4}$.

De esta manera, los relatos biográficos permiten a los individuos una de las formas de acceso a su experiencia en el marco de contextos socio-históricos situados, dejando emerger las conexiones complejas entre lo individual y lo social ${ }^{5}$. Como menciona Delory-Momberger:

Lo que hace aparecer esta lógica de subjetivación y de apropiación biográfica, es la dimensión socializante de la actividad biográfica, el rol que ella ejerce en la manera como los individuos se comprenden ellos mismos y se estructuran en una relación de co-elaboración de sí y del mundo social. Que ellas tomen la forma de inscripciones de acción, de construcciones mentales, de narraciones de vida, las «historias» que nos contamos a nosotros mismos y aquellas que le recitamos a otros, lejos de remitirnos a una intimidad inaccesible, tienen por efecto acordar nuestro espacio-tiempo individual con el espacio-tiempo social. Ellas implicitan un conocimiento y una práctica de los contextos, de los espacios sociales, de los modos de acción y de comportamiento; ellas ponen en intriga una racionalidad y una operatividad social en la que nos mezclamos ${ }^{6}$.

El trabajo con registros biográficos desde una perspectiva histórica adquiere relevancia en la coyuntura actual de Colombia, en la que las políticas públicas han situado a la víctima en el centro de las preocupaciones y se interesan por comprender sus puntos de vista en torno al conflicto colombiano, no solo para dar cabida

4 Joan Pujadas, «El método biográfico y los géneros de la memoria». Revista de Antropología Social, $\mathrm{n}^{\circ} 9$ (2000): 127-158.

5 Maurice Halbwachs, La memoria colectiva (Zaragoza: Prensas Universitarias de Zaragoza, 2004), 25-46.

6 Christine Delory-Momberger, «Lo Biográfico: una categoría antropológica» en, Biografía y formación. Narración de sí e Investigación, comp. Martha Sarria Materón (Cali: Universidad del Valle, 2007), 71. 
desde el punto de vista humanitario a sus sentires, preocupaciones y expectativas en el marco de una sociedad posconflicto, sino también para tener un panorama más amplio en torno a los sucesos de la guerra que marcaron con su dinámica, tanto a los sujetos como a los entornos sociales en los que transcurrían sus interacciones. Todo ello permite como sociedad, no solo conocer desde el punto de vista de los sujetos los fenómenos transcurridos, sino que, al mismo tiempo, estos sirven como soportes para tomar posiciones éticas sobre lo acontecido. En este sentido, para Elsa Blair, «pese a la importancia de que los testimonios tienen una enorme fuerza política, esta última solo se potenciará cuando la sociedad asuma la condena moral necesaria ante los hechos que han vulnerado a sus integrantes y los han puesto en el lugar de víctimas» ${ }^{7}$.

De este modo, en el presente artículo abordaremos la reflexión y análisis del relato biográfico de un profesor de filosofía, el cual fue elaborado a partir de varios encuentros concertados con él, en el marco de una investigación cuya preocupación se centra en la configuración de los sujetos en contextos de violencia política en América Latina. En la primera parte del artículo exponemos algunos aspectos sobre la violencia política en Colombiay el contexto específico en el que se sitúa el relato testimonial y cómo estos emergen en él. En la segunda se profundiza en las apreciaciones en torno a las vivencias del entrevistado en la zona del Magdalena Medio. En la tercera exponemos las transformaciones ocasionadas en el sujeto por las vivencias y como estas recabaron en sus actuaciones como sujeto político y cómo maestro. Finalmente, a manera de conclusiones, se hace énfasis en el posicionamiento de los registros biográficos y testimoniales en Colombia para acceder al estudio de las subjetividades, así como en la importancia de su abordaje por parte de los investigadores que trabajan en el campo de las ciencias sociales y se preocupan por la historia reciente. En términos de organización de la estructura del artículo, dimos preferencia a los pasajes del relato en los que aflora la problemática

7 Elsa Blair Trujillo, «Los testimonios o las narrativas de la(s) memoria(s)». Estudios Políticos, no 32 (2008): 113. 
de interés y al análisis sobre ellos, dejando los posicionamientos teóricos o las aclaraciones de tipo histórico a nivel de paratextos ${ }^{8}$.

\section{Los caminos de la vida: Intersecciones entre Memoria e Historia}

El testimonio es una forma de memoria (...) luchando contra lo que podemos llamar memoria disruptiva, es un esfuerzo de reconstruir algo similar a una continuidad en la vida como si fuera una existencia normal ${ }^{9}$.

La constitución de sujetos en los actuales contextos latinoamericanos se caracteriza por la multiplicidad de campos y de agentes que intervienen en su formación e interpelan de manera diversa a los sujetos, incidiendo en sus procesos de subjetivación y contribuyendo a modular sus sensibilidades, formas de razonamiento y modalidades de actuación. Una de estas dimensiones la constituye el campo de lo político y sus nexos con la violencia, la cual se ha configurado como una impronta en la memoria social en los países latinoamericanos en el siglo XX y comienzos del XXI, en los cuales el recurso a la violencia ha sido casi obligado, o por lo menos recurrente, para acceder al poder político y/o para obstaculizar el paso a los oponentes. A esto se han referido de manera insistente los historiadores y cientistas políticos que han abordado el análisis del discurrir de lo político en el caso colombiano ${ }^{10}$. En este sentido María Teresa Uribe afirma que:

[...] las formas de ser ciudadano y de hacer ciudadanía en Colombia transitan por caminos distintos de aquellos trazados por la imaginación filosófica y jurídica; en cambio, en los entrecruzamientos entre la guerra y la política, entre las violencias y las transacciones, entre las intermediaciones y la

8 Para Genette algunos de los elementos que hacen parte de los paratextos de una obra son título, subtítulo, intertítulos, prefacios, epílogos, advertencias, prólogos, notas al margen, a pie de página, finales; epígrafes. Estos paratextos hacen parte, en sus palabras, de la pragmática de la obra, es decir de la voluntad del autor de incidir en el lector, no solo desde el intertexto, sino desde la estructura total de la obra y sus diversos componentes. Véase: Gerard Genette, Palimpsestos. La literatura en segundo grado (Madrid: Taurus, 1989), 11.

9 Lawrence Langer, Holocaust Testimonies. The ruins of memory (New Haven and London: University Press, 1991), 3.

10 Daniel Pécaut, Guerra contra la sociedad (Bogotá: Planeta, 2001), 9-20. 
fuerza, entre la palabra y la sangre, se configura un ciudadano posible, el realmente existente, que no es tan virtual ni tan deficitario como algunos lo quisieran ver, ni tan cívico como otros anhelarían que fuera ${ }^{11}$.

Dentro de este horizonte problemático surgen interrogantes referentes a ¿qué marcas de la violencia política contemporánea pueden ser leídas en diferentes contextos en nuestro país? y a ¿cómo se configuran y reconfiguran los sujetos cuando son interpelados en torno a sus trayectorias, a sus recuerdos y olvidos sobre acontecimientos de violencia política? Así, en el presente artículo nos detenemos en el análisis de un relato testimonial específico, al querer focalizar la mirada en un solo sujeto e intentar captar sus vivencias y apreciaciones sobre la violencia política, así como la incidencia del mismo relato sobre su subjetividad ${ }^{12}$. En este sentido, como menciona Cornejo:

[...] el relato puede concebirse como la puesta en escena de uno por uno, en que eventos pasados son puestos en intriga por un narrador, siempre llamado a la pregunta por el sentido y la unidad de su vida. Así, el relato permite la apropiación subjetiva de su historia, movilizando, por la resignificación de su vida, el poder de transformarse. En este sentido, el relato no es estático, y lo dicho no está dicho de una vez y para siempre. El relato está vivo, justamente porque da cuenta de un individuo también vivo, en constante cambio y transformación $[. . .]^{13}$.

Las expresiones contemporáneas de la violencia, en el contexto colombiano, han dejado sus improntas en la formación política de los colombianos, por lo menos desde el período conocido como la Violencia, para hablar en términos recientes, pues no podemos olvidar que el siglo XX comenzó con la Guerra de los Mil Días (1889 -1902). Lo cierto es que, en la memoria de los contemporáneos, con todo su arco generacional y sus diferentes énfasis memoriales, los recuerdos de la violencia de

11 María Teresa Uribe, "El republicanismo patriótico y el ciudadano armado», Estudios Políticos, n ${ }^{\circ} 24$ ( 2004): 92.

12 Fortunato Mallimaci y Verónica Giménez Béliveau, «Historias de vida y método biográfico» en Estrategias de Investigación cualitativa, comp. Irene Vasilachis (Barcelona: Gedisa, 2006), 186.

13 Marcela Cornejo y Francisca Mendoza y Rodrigo Rojas, «La Investigación con Relatos de Vida. Pistas y Opciones del Diseño Metodológico", Psykhe, $\mathrm{n}^{\circ} 1$ (2008): 3, https://doi.org/10.4067/S0718-22282008000100004. 
los años cincuenta es la que se percibe más cercana en el plano de la temporalidad, representando, para buena parte de los colombianos, el referente al que asocian las actuales expresiones de violencia política. Como parte de esta memoria se encuentra el asesinato de Jorge Eliécer Gaitán, el 9 de abril de 1948, identificado como un acontecimiento fundante, en el sentido de que para muchos colombianos todo empezó aquel 9 de abril. Un recuerdo imborrable legado de padres a hijos, de abuelos a nietos, en el que la memoria de lo político se bifurca entre liberales y conservadores ${ }^{14}$, pero también entre pueblo y oligarquía, entre asesinos sin rostro y duelos nunca claramente establecidos.

En las décadas que siguieron a esta coyuntura política el panorama social, cultural y político del país cambió sustancialmente y a la violencia bipartidista se le mezclaron otros actores políticos, otras organizaciones sociales y otras violencias de distinto orden ${ }^{15}$. De las cenizas del bipartidismo surgió la amenaza y el miedo en torno a opciones políticas diferentes, dentro de un contexto internacional que siguió enfrentando el fantasma de opciones distintas al modelo capitalista, léase socialismo, comunismo o movimientos de liberación nacional, en donde quienes vehiculizaban proyectos diferentes a los hegemónicos fueron enfrentados como el Otro a ser devastado y aniquilado. De allí surgen en nuestro país otras memorias, la memoria que se relaciona con los grupos guerrilleros, la memoria de los paramilitares y la guerra "anti-subversiva», que han marcado el imaginario político desde los años 60 hacia acá, con diferentes tonalidades, bajo el resguardo de la mal llamada seguridad nacional. Memorias que se intersectan y adquieren configuraciones

14 La incidencia de la memoria política liberal-conservadora en buena parte de las generaciones que enmarcan su vida en el siglo XX colombiano y sus maneras de permear los entramados de la vida cotidiana de los sujetos puede apreciarse en lo que nos relata Ricardo, cuyo relato de vida analizamos en el presente artículo, cuando alude a sus memorias de infancia y sus recuerdos escolares: «Mi mamá recibió la libreta junto a las felicitaciones por mi desempeño, cuando llegamos a la casa me dijo: mijo, las buenas notas vienen en color azul como los conservadores y las malas en rojo como los liberales. Comprendí años más tarde que mi vieja me había dado mi primera clase de cultura política y me señalaba la gran tradición bipartidista del país».

15 Adolfo León Atehortúa Cruz, Prólogo a Memoria y Formación. Configuraciones de la subjetividad en ecologías violentas, de Martha Herrera y otros (Bogotá: Universidad Pedagógica Nacional, 2013) 10-14; Gonzalo Sánchez, Guerras, memoria e historia (Medellín: La Carreta, 2006), 65. 
particulares de acuerdo con las distintas coyunturas y a los actores que las activen. Con estas memorias coexisten memorias subalternas, subterráneas, que se constituyeron al margen de las versiones oficiales, memorias de resistencia que entretejen otros imaginarios sobre estos acontecimientos, y configuran comunidades de memoria que acrisolan otras formas de imaginar el orden social y el lugar de los sujetos dentro de él, en la pugna por avizorar otros mundos posibles.

Ricardo, seudónimo que encubre el nombre real de uno de nuestros entrevistados en el marco de la investigación, tenía en el momento de nuestro encuentro 47 años, es filósofo de formación y tiene estudios en teología. Actualmente es profesor en un colegio privado en los grados 10 y 11 e interactúa con estudiantes que oscilan entre los 14 y los 15 años de edad. Su vida ha estado marcada por una niñez y juventud con privaciones económicas, gran sentido del sacrificio y esfuerzo personal para estudiar y tener una calidad de vida satisfactoria. A la edad de 19 años ingresó a la comunidad de los jesuitas para seguir la carrera del sacerdocio, retirándose momentos antes de ser consagrado como sacerdote, a la edad de 32 años. Este pasaje de su formación le configura como un sujeto con compromiso y entrega social y ha determinado sus experiencias de trabajo comunitario en las cuales la docencia ha estado presente de diversas maneras.

En el momento de la entrevista, la experiencia más reciente y decisiva en su vida, y en torno a la cual articula los hechos rememorados sobre violencia política, se refiere a su vocación sacerdotal y a las dudas que se le presentaron sobre continuar este camino o abandonarlo de manera definitiva. De este modo sus afectos y desafectos, juicios y raciocinios sobre las vivencias relacionadas con violencia política, en el marco de trabajos comunitarios, han tenido como brújula el mandato que le dejó su mamá a lo largo de su infancia, así como el pasaje por la comunidad jesuítica, mandato relacionado con servir a los demás de manera desinteresada. Pero también, a ello se unen las dudas que lo embargaron de manera recurrente sobre el camino del sacerdocio y cómo lograr dar cumplimiento a este mandato de entrega a los demás que se había constituido como una fuerte impronta en su 
subjetividad. Por lo menos es así como quiso mostrarse frente a sí mismo y frente a nosotros en el relato que fue elaborando en el marco de nuestros encuentros, pues no hay que olvidar que entrevistador y entrevistado interactúan de manera compleja. En palabras de Cornejo: «El relato de vida siempre es dirigido a alguien y construido en función de lo que dicha situación de enunciación representa, de las interacciones que en ella tienen lugar y de los efectos que el narrador espera producir sobre sus destinatarios $\rangle^{16}$. En este mismo sentido Pollak precisa que:

Los momentos elegidos y las razones invocadas para contar la propia vida moldean las principales modalidades dela composición de los relatos, y muy probablemente de la estructuración de la memoria... Al igual que el lugar del testimonio en el tiempo, la organización cronológica de la narración se encuentra fuertemente en función del tipo de necesidad al cual responde el hecho de testimoniar, y del tipo de recursos movilizados para lograrlo - estando ambos ligados al grado de generalización de la experiencia que el sujeto pueda permitirse ${ }^{17}$.

En Ricardo están presentes las marcas de su generación y el bagaje cultural y político que la signó, marcas en las que se perciben los ecos de la revolución cubana, la teología de la liberación, mayo del 68, la circulación de nuevos modelos culturales, además de la presencia de grupos guerrilleros de izquierda y de grupos paramilitares ${ }^{18}$. Cuando se llevaron a cabo nuestros encuentros en Bogotá habían pasado ya varios años de las vivencias que nos narró, asegurando que antes no había tenido la oportunidad de reflexionar sobre ellas y que solo ahora, en el contexto de Bogotá y de la toma de distancia que permite el paso de los años, lograba articular reflexiones en torno a ellas. Como dice Pollak:

Entre aquel que está dispuesto a reconstruir su experiencia biográfica y, aquellos que le solicitan hacerlo o están dispuestos a interesarse por su historia, se establece una relación social que define los límites de lo que es efectivamente decible...Pero esa misma posibilidad de tornar públicos sus recuerdos condiciona

16 Cornejo y Mendoza y Rojas, «La investigación con relatos de vida. Pistas y Opciones del Diseño Metodológico,» 3.

17 Michel Pollak, Memoria, olvido, silencio. La producción social de identidades frente a situaciones limite (La Plata: Ediciones al Margen, 2006), 80-81.

18 Fabio López De La Roche, Izquierda y Cultura Politica ¿Oposición alternativa? (Santa Fe de Bogotá: CINEP, 1994), 55-92. 
por su parte el trabajo realizado para superar la crisis de identidad que está en el origen de la necesidad, y de la dificultad, de testimoniar ${ }^{19}$.

Cuando Ricardo rememora sus vivencias sobre el conflicto armado colombiano, y en general sobre la violencia política, ancla sus recuerdos en ejes territoriales que signaron el horizonte espacio-temporal y las características de sus vivencias. Estos gravitan alrededor del Magdalena Medio (y lugares como Barrancabermeja, San Pablo, Puerto Wilches) y Bogotá. En estos lugares se dieron hechos y se entrecruzaron actores que marcaron su memoria y sus experiencias sobre política, así como sus opiniones sobre lo ético y sus implicaciones en el ejercicio de la docencia y en su actuar cotidiano, configurándose como sujeto político al fragor de los acontecimientos vividos.

Cuando Ricardo somete a examen las condiciones de acción social y de docencia que fueron posibles en estos espacios, se evidencia en su relato las modulaciones que la violencia tuvo en el plano regional, siendo más desembozada en unos lugares que en otros, sometiendo a los sujetos a procesos de subjetivación más dolorosos, como es el caso de San Pablo, Puerto Wilches y Barranca, en una ecuación perversa que equipara lugares con menor desarrollo e infraestructura con condiciones más crudas de violencia. Pero también en el relato se dejan entrever otras marcas culturales en las que, en casos como el de Bogotá, el anonimato urbano, así como valores más seculares facilitan la coexistencia de grupos e ideologías diferentes, por lo menos en buena parte de la ciudad, así como la sensación de poder hablar sobre los actores armados y el conflicto político. Las vivencias narradas por nuestro entrevistado en estos lugares nos proveen una forma de tomar el pulso al tipo de recuerdos y olvidos que han entrelazado las memorias de los colombianos sobre violencia y política, sus marcas en la subjetividad, en sus actuaciones presentes y en sus horizontes de futuro.

19 Michel Pollak, Memoria, olvido, silencio. La producción social de identidades frente a situaciones límite, 56. 
Ricardo se refiere a las circunstancias que lo llevaron a dejarse entrevistar y a escribir sus relatos como parte de las interpelaciones ocasionadas por su actual formación universitaria, en la que se habilitaron espacios para discutir temas referentes a la violencia política en Colombia, pero también porque ya se siente preparado para hablar sobre asuntos que vivenció y puede proceder a tramitarlos subjetivamente:

Ustedes son los primeros que van a escuchar esto. Pacho me dijo cuando nos despedimos: todas esas cosas que te han pasado escríbelas!! pero uno con el dolor no es capaz, ese es el problema, no es capaz de darle una lógica. Hoy los relatos surgen con fuerza pero más tranquilamente, quizá más coherentemente, tienen un principio, tienen un fin, que uno no sería capaz de verlo en el sitio en que le sucedieron y con el problema encima, ¿si?, un dolor... digamos, uno enfermo lo que quiere es que le curen el dolor, uno quiere que le quiten esa amenaza a la vida y le digan nos equivocamos, pero eso no iba a pasar, entonces yo opté por salir. Entonces el discernimiento es qué debo hacer con mi vida, cómo la he vivido y qué vale la pena de ser vivido. Yo creo que lo que vale la pena de ser vivido es que la vida de uno se vive con otros, para los otros, desde los otros, no una vida solo, nooo!!!20.

En la conversación iniciada con Ricardo surge, casi de inmediato, su ingreso en el noviciado dentro de la orden de los jesuitas, como uno de los anclajes identitarios que entrelazados con su formación religiosa, con los años en los que estuvo más expuesto a situaciones caracterizadas por violencia política. Por ello le pedimos que nos contara hasta donde había llegado en su carrera sacerdotal.

Alcancé a estudiar hasta toda la teología, lo único que no hice fue ordenarme. Entonces, a raíz de eso ya tenía experiencia como profesor. Había trabajado en Manizales, en San Bartolo, obviamente yo tenía una inclinación docente desde pequeño pero esto lo reforzaba la comunidad por su campo más amplio de apostolado, por lo que tiene muchos colegios en Colombia. Cuando me retiro digo que no quiero por ahora continuar en la docencia, quiero abrir un espacio distinto a mi vida. Me retiré por razones muy personales, fue una

20 Ricardo (Profesor de Filosofía), entrevistado por Martha Cecilia Herrera y Vladimir Olaya, 28 octubre de 2016. 
decisión propia, vi que no era el camino para mi vida, eso lo pensé como cuatro o cinco años; es decir casi toda la teología.

Antes de irme a la teología yo quise tener una experiencia pastoral, yo venía de una experiencia de colegios y le dije al provincial de ese tiempo mi decisión y me fui al Magdalena Medio. En Barranca viví en un sector que se llama el 9 de abril, una zona cercana al aeropuerto que tradicionalmente ha sido dominada por los paras y la guerrilla. Era un sector dominado netamente por los elenos sobre todo. Entonces empieza el despertar de lo político, que en la filosofía había sido una de las cosas que yo quería estudiar y me quedé con la... no frustración... pero me quedé con la idea de hacerme... yo quería ser politólogo, porque ya había estudiado la filosofía y me interesaba lo político, así, en términos generales, lo político. En ese tiempo no había la presencia de los paramilitares y la gente se acostumbró a vivir con la guerrilla, sabía quien era guerrillero, sabía que equis familia tenía un hijo en la guerra, allá no le llaman guerrillero sino en la guerra. Y entonces esa situación personal me lleva a replantearme mi vida y pido que me saquen de allá. Eso fue como entre el 96 y el 98, algo asíi ${ }^{21}$.

\section{Al preguntársele en qué consistía el trabajo pastoral al que se vinculó en esta región, Ricardo deja emerger un lenguaje cargado de profundo humanismo cristiano:}

Yo acompañaba comunidades de base, era en los barrios muy pobres, acompañaba unas reuniones un poco a la manera de las CEBS (Comunidades Eclesiales de Base) del Brasil ${ }^{22}$,

21 Ricardo, entrevistado.

22 «Las Comunidades Eclesiales de Base (CEBS) son uno de los aportes más significativos de la Iglesia L.A. a la Iglesia mundial. Recogen la tradición más antigua de la Iglesia, la de las primeras comunidades apostólicas y entroncan a la vez con la perspectiva actual del Vaticano II que, al destacar, el concepto de Iglesia como Pueblo de Dios, hace más fácil su surgimiento». Daniel Camarero. «Las comunidades eclesiales de Base. Perspectiva latinoamericana». Acceso el 6 de noviembre de 2016, http://mercaba.org/ Pastoral/C/comunidades_eclesiales_base_LA.htm. «En 1955, en Río de Janeiro, se fundó la Conferencia Episcopal Latinoamericana (CELAM), institución conocida por las declaraciones en la II Asamblea General celebrada en Medellín en 1968 al denunciar con un profetismo, inusual en la Iglesia Latinoamericana, la situación de injusticia, miseria, violencia en el continente (...) en esa conferencia, se decide, basándose en la experiencia de la Acción Católica, promover la organización de Comunidades Eclesiales de Base, las cuales debían usar el método de la Revisión de Vida (Ver, Juzgar, Actuar)». Bidegaín, «Las comunidades eclesiales de base (CEBs) en la formación del partido dos Trabalhadores (P.T.)», 95.

En Brasil las «CEBs se convirtieron en un nuevo movimiento social a partir de su praxis cristiana que posibilitó el desarrollo de prácticas de sociabilidad integrativas y espacios alternativos que facilitaron la articulación del tejido social popular para el retorno a la democracia» Fabián Bustamante, «La participación de las comunidades 
estaban llegando los ecos acá y era una lectura de la realidad humana desde el evangelio, una iluminación bíblica digámoslo así. También se ofrecía apoyo a los profesores de la escuelita Fe y Alegría en capacitaciones, en acompañamiento espiritual, vivíamos muy pendientes de las necesidades de la gente ${ }^{23}$.

Acontinuación, Ricardo reitera sus dudas sobre continuar o no con la carrera religiosa y la necesidad de encontrar un ambiente propicio para lo que él llama discernimiento, aludiendo a condiciones en las cuales no sienta presión de ningún tipo, lo cual paradójicamente está en contravía con la realidad del país y con su persistente búsqueda por asumir un compromiso político y comunitario que dotara de sentido el trabajo educativo.

Yo sentía que las obras sociales eran unas obras que no tenían la fuerza que hoy tienen, como por ejemplo el Servicio Jesuita a Refugiados, el SJR, que en esa época no tenía la fuerza que tiene ahora, estaba comenzando... de hecho estuvimos en su fundación; había unas parroquias y estaba comenzando Desarrollo y Paz para el Magdalena Medio con Pacho de Roux. Entonces yo decía que la educación me gustaba pero sentía que la educación está dentro de la institucionalidad y que hay otras cosas que son realmente importantes que no son estrictamente educativas sino políticas y son tan urgentes como eso, entonces volví de nuevo al Magdalena Medio y me fui a trabajar con el proyecto de palma ${ }^{24}$.

En su relato sobre el discernimiento político está en juego su proyecto de vida y las decisiones que toma en función de su compromiso social. Su narrativa indica los esfuerzos de un sujeto que busca tomar las riendas de lo que considera su destino y los caminos que lo llevan a él contando como capital cultural con una excelente formación escolarizada, de la mano de su educación religiosa que le posibilita capacidad reflexiva, adquirida a

eclesiales de Base (cebs) en la regeneración del tejido social popular brasileño durante la dictadura militar 1964-1985» Revista Encrucijada Americana. n 1. (2009): 178.

Un texto que alude a los compromisos sociales vinculados a la teología de la liberación y las comunidades de base en Colombia es el de: Inés Claux Carriquiry, La búsqueda. Del convento a la revolución armada. Testimonio de Leonor Esguerra (Buenos Aires: Aguilar, 2011), 95-132.

23 Ricardo, (Profesor de Filosofía), entrevistado por Martha Cecilia Herrera y Vladimir Olaya, 12 de noviembre de 2016.

24 Ricardo, entrevistado. 
través de las prácticas espirituales forjadas en el seminario y, probablemente, del método de la Revisión de Vida: Ver, Juzgar, Actuar, característico de las Comunidades Eclesiales de Base ${ }^{25}$, así como de sesiones psicoanalíticas a las que se sometió para tramitar mejor sus vivencias. En este sentido, su relato nos deja ver toda una hermenéutica del sujeto en la que este está dispuesto a someterse a examen y lograr transformaciones de orden subjetivo, calificando el tipo de experiencias que las propician como de vaciamiento:

Y estando ahí yo [en el Magdalena Medio] dije pues bueno... en mi vida mi mamá me enseñó siempre a servir: hay que hacer el bien mijo a cualquier persona... Había tomado la opción del sacerdocio que creía que era la más cercana, la que mejor lo hacía. Y después dije: no, yo creo que puedo hacerlo sin volverme cura, un poco la idea me fue trabajando y también era un poco costoso, no lo voy a negar, la cuestión del celibato... Y no quise seguir en esa vida, me parece una buena opción y viví feliz, los mejores años de mi vida, mi juventud toda la dediqué a eso de lleno. Yo fui un muy buen religioso puedo decir. Salí limpiamente, con una renuncia muy clara, con un acompañamiento psicológico y yo quería estar muy seguro de lo que iba a hacer... Entonces me metí a hacer psicoanálisis, tres sesiones semanales, fue una catarsis y una limpieza ... una ...digamos profilaxis del alma, remover cosas muy antiguas, más los retiros y el acompañamiento de mi asesor espiritual ${ }^{26}$.

\section{Masacres, impunidad $y$ poderes enfrentados: vivencias en el Magdalena Medio}

La experiencia viva no da conocimiento. El conocimiento lo obtenemos a través del relato, que se convierte de este modo en lo que los comunicólogos llaman referente primordial ${ }^{27}$.

Como ya habíamos mencionado, Ricardo solicitó a su superior en la comunidad jesuita ser enviado en misión pastoral a Barrancabermeja en su propósito de tener mayor contacto con

25 Ana María Bidegaín, «Las comunidades eclesiales de base (CEBs) en la formación del partido dos Trabalhadores (P.T.)» Historia Crítica, $\mathrm{n}^{\circ} .7$ (2017): 92-109.

26 Ricardo (Profesor de Filosofía), entrevistado por Martha Cecilia Herrera y Vladimir Olaya, 16 de noviembre de 2016.

27 Manuel Cruz, «Tiempo de narratividad. El sujeto, entre la memoria y el proyecto» Análisis, nº 25 (2000): 30. 
la comunidad o «la gente» (como él la denomina). En el relato sobre su llegada a la zona y su contacto con los pobladores emergen significaciones propias de la cosmovisión del mundo de las Comunidades Eclesiales de Base y su forma de articular 'Dios y Pueblo' bajo la categoría de el pobre, en donde el peso se inclina hacia este último como el dador de sentido para la acción política:

\begin{abstract}
Me fui con $\$ 300.000$ a Barranca llegué y había unas familias conocidas con las que ya había trabajado y la isolidaridad del pobre es tan verraca! Es la humanidad que camina, es que si ustedes lo vieran desde el punto de vista teológico se diría que es la divinidad misma haciendo cosas por uno. Me dicen: no Ricardo tú no te vas a un hotel, ven a nuestra casa. Ahí voy con el Programa Desarrollo y Paz. Yo era el director del componente social, el trabajo consistía en ir a visitar familias, yo digo que hacer legible el proyecto. La palma es un cultivo muy preciso, ese proyecto me enseñó que si la gente tiene un producto en una tierra (en términos de la ciudad una inversión) la gente defiende un poquito más la tierra. Eso va a ser importante para analizar fenómenos de desplazamiento. Cuando la gente se ha empoderado de algo y tiene conciencia de lo que es suyo lucha por ello ${ }^{28}$.
\end{abstract}

Desde su relato Ricardo da cuenta de las transformaciones dadas en varias regiones del país fruto de la violencia política, dentro de las cuales se encuentra el Magdalena Medio que han sido captadas por los trabajos periodísticos e historiográficos. Esta es una zona en la que en un comienzo había presencia guerrillera y frente a la cual la población adoptó formas de sobrevivencia específicas teniendo que afrontar, posteriormente, otras situaciones debido a la presencia de grupos paramilitares que llegaron a disputar el territorio y a posicionarse a través de las masacres ${ }^{29}$. Al referirse a estos fenómenos emergen en el relato de

28 Ricardo, entrevistado.

29 «Las masacres aparecieron a mediados de los ochenta como una forma de intimidación de los paramilitares en poblaciones bajo el control territorial de la guerrilla en zonas como Urabá, el Magdalena Medio y el Meta. A mediados de los noventa reaparecieron por todo el país como un sello de la presencia y barbarie de los paramilitares... Pero sería el período comprendido entre 1997 y 2003 en el que se registraría la explosión de esta práctica de violencia extrema. En esta época se presentan masacres en forma persistente en regiones donde desde 1997 realizaron incursión las autodefensas... En el sur de Bolívar los grupos de autodefensas lograron una presencia muy importante en San Pablo y Cantagallo, municipios que el ELN 


\title{
Ricardo los poderes enfrentados y los modos diferenciados con los que la población percibe los actores armados y las masacres que marcaron la incursión paramilitar:
}

\begin{abstract}
En palabras de la gente, un campesino me decía: Ricardo es que ahora es difícil... lo mejor sería que mande uno solo, pero cuando mandan dos a quién uno le obedece? Qué quiere decir eso: que cuando estaba la guerrilla ellos como que ya sabían quién era la guerrilla y qué buscaba, cómo era su actuar dentro de la zona. Cuando llegan otros llegan sembrando terror, se incrementa la violencia y la forma como se mata a la personas; la guerrilla podía hacerte un atentado o una bomba, o que se yo, pero la guerrilla habitualmente te sacaba y te mataba o mataba a equis persona, pero es que esto ya era en cualquier momento del día o de la noche... a una persona la degollaron delante de todos y el que lo tocara o lo auxiliara se moría. ¿Se imaginan lo que eso significa para una comunidad, ver a una persona muriéndose y no poder hacer nada porque el siguiente muerto eres tú? Cuando llegan los paramilitares en Barranca mataron 25, cuando entran a San Pablo matan 12, ahí cayeron profesores, de todo... gente pobladora de la región, normalita ${ }^{30}$. La masacre en Barranca fue la del Barrio 9 de abril y María Eugenia. El año no lo se con precisión yo tendría que es 95 o 96, que se yo una cosa así, un poquito antes quizá. El hecho es que aparecen unas camionetas con vidrios oscuros y empiezan a aparecer las consignas de MAS: MUERTE A SECUESTRADORES, en principio todo este cuento
\end{abstract}

había pedido fueran rodeados de las garantías de seguridad necesarias para la realización de la Convención Nacional». Ver: «Masacres. La ofensiva paramilitar» Verdad Abierta, Bogotá, 2 de septiembre de 2008, acceso el 17 septiembre de 2017, http://www.verdadabierta.com/nunca-mas/masacres/202-masacres-el-modelocolombiano-impuesto-por-los-paramilitares).

30 «El 8 de enero de 1999 fueron asesinadas 14 personas en el casco urbano de San Pablo por sicarios paramilitares delante de militares y policías, 4 heridos sobrevivieron a la matanza. Ex alcalde del municipio, candidato a la alcaldía, profesores, ama de casa, menor de edad, empleados, jornaleros, campesinos, personas del común que departían en lugares públicos. Y hasta allí les llegó la muerte. Apareció un grupo de paramilitares al mando de Julián Bolívar quienes venían con la orden expresa de matar a todo el que estuviera en el camino porque hacían parte de la guerrilla de las Farc... Doce años después las familias aún no han tenido respuestas sobre sus seres queridos y sólo se quedaron con un auxilio fúnebre de $\$ 400.000$ que les dio la gobernación de Bolívar para gastos mortuorios. Las familias se sienten solas, desamparadas de las leyes y de la justicia y ni siquiera han podido dignificar el nombre de sus seres queridos porque el autor intelectual en versión por la Ley de Justicia y Paz anotó que ellos tenían plenamente confirmado que estas personas hacían parte de las guerrillas de las Farc». Asociación Campesina del Valle del río Cimitarra. «[Colombia] La masacre de San Pablo (Sur de Bolívar). Conmemoran los 14 años de la matanza», Kaos en la Red, Colombia, 6 de enero de 2013, acceso el 21 de marzo de 2013, http:/kaosenlared.net/ america-latina/item/42850-colombia-la-masacre-de-san-pablo-sur-de-bolivar-conmemoranlos-14-a\%C3\%B1os-de-la-matanza.html. 
de las AUC, y en esa entrada matan 25 personas de manera selectiva o no, no lo sabemos, pero son $25^{31}$.

Cuando Ricardo rememora sus experiencias y las de sus allegados no recuerda con precisión las fechas en las que ocurrieron los hechos narrados. La masacre en Barrancabermeja tiene lugar en mayo de 1998 (Ricardo dice: El año no lo sé con precisión yo tendría que es 95 o 96, que se yo, una cosa así, un poquito antes quizá). Este descompás temporal de su relato es una de las características de la memoria, enfrentada siempre a una sucesión de recuerdos y olvidos en la que el fluir de la temporalidad pareciera tener continuidad y que contrasta con la reconstrucción histórica para la que el tiempo está marcado por la medición precisa de los acontecimientos. Esto indica que para el sujeto que rememora lo significativo son los hechos que le impactaron, a veces sin algunos de sus detalles, y nos muestra a su vez la importancia

31 «El sábado 16 de mayo de 1998, hacia las 8:30 p.m., unidades de la estrategia militar encubierta de tipo paramilitar, incursionaron en un sector del suroeste de la ciudad de Barrancabermeja y ejecutaron extrajudicialmente a 7 hombres y desaparecieron forzadamente a 32 más, entre ellos a una mujer. Los hechos ocurrieron en una cancha de fútbol del sector, donde celebraban un bazar, allí las primeras víctimas. Luego siguieron su recorrido de horror hacia el barrio "9 de Abril" donde ingresaron en varios establecimientos públicos y continuaron sus crímenes. El 3 de enero del 2001, fue vinculado al proceso el paramilitar MARIO JAIME MEJÍA, conocido como "El Panadero", quien se acogió a los beneficios contemplados en la Ley 975 "Para la Justicia y para la Paz", y el 18 de abril del 2008, el periódico El Tiempo publicó apartes de la versión dada por "El Panadero" ante un Fiscal de la Ley 975 en la ciudad de Medellín. Desde el 19 de enero del 2002, a través del Colectivo de Abogados "José Alvear Restrepo", fue presentado el caso ante la CIDH. Hoy se espera que ante la negación de Justicia en Colombia, se pueda tomar una decisión de fondo por parte de la CIDH que favorezca a los familiares y dignifique a las víctimas de estos crímenes de Lesa Humanidad. Una decisión que logre la ubicación de las fosas, poder hallar a sus familiares desaparecidos y afirmar el derecho a exhumar a sus seres queridos, darles cristiana sepultura y tener un lugar donde visitarlos, llorarlos, llevarles una flor y una canción. Han pasado 10 años de la masacre y desaparición forzada realizada por la estrategia militar encubierta en Barrancabermeja. Han pasado 10 años de una investigación sinuosa en la que se ha negado el derecho a la verdad y a la justicia. Han pasado 10 años, en los que la impunidad ha garantizado la perpetración de nuevos crímenes de Lesa Humanidad en el puerto petrolero, entre ellos el de varios testigos de los hechos del 16 de mayo de 1998». «10 años de Impunidad de la Masacre en Barrancabermeja» Comisión Intereclesial de Justicia y Paz, acceso el 13 de julio de 2017, http://justiciaypazcolombia.com/10-anos-de-Impunidad-dela-Masacre. «Al año de la masacre, el Tribunal Internacional de Opinión, TIO, reunido en Montreal, Canadá, declaró culpable al Estado colombiano por acción, omisión e impunidad en la masacre de 7 personas y la desaparición de 25 más el 16 de mayo de 1998 en Barrancabermeja». "La masacre de Barranca en las cortes internacionales» Verdad Abierta, Bogotá, 17 de marzo de 2009, acceso el 15 de mayo de 2017. http://www. verdadabierta.com/index.php?option=com_content\&id=2277. 
para el investigador, o también para el mismo sujeto que hace un trabajo de memoria de carácter más anamnético, de contar con otras fuentes que permitan contrastar las versiones y delimitar los hechos con precisión; aspecto que señala las tensiones entre memoria individual y memoria histórica ${ }^{32}$.

Ricardo no estuvo en la región cuando ocurrieron las masacres, pero afirma poder ver/sentir los efectos de las mismas, en una especie de dispositivo que permite que la memoria, a través del voz a voz, se vaya incorporando en los miembros de una comunidad dando cuerpo a memorias sociales en las que los relatos conforman repertorios comunes, pérdidas y duelos colectivos.

Los efectos fueron, por ejemplo, la ausencia de las personas, porque ya a algunas las había visto, las había tratado, en un barrio uno conoce a muchos. Entonces el dolor, la pena de haber perdido ese conocido, ese amigo, eso fue difícil...Y ver la tristeza en que se sume todo un barrio o todo un pueblo. Los efectos son la ausencia de gente en la calle, la pérdida de la alegría, la pérdida de confianza, digamos que lo primero que laceran estos grupos es la confianza de un hombre hacia el otro, ya no lo ves como un amigo sino como un potencial enemigo, las vidas ya no se socializan, se ocultan, porque entonces el otro puede leer que este es un auxiliador, entonces ya casi nadie cuenta lo que antes era una cosa fluida, saber del otro, hoy se vuelve ya el anonimato. Se da un quiebre en los lazos de sociabilidad. Hay una pérdida de confianza en instituciones como las fuerzas militares, la gente no confiaba en el ejército, no confiaba en la policía porque entendía que su posición no eran clara frente a los actores. Después se fue clarificando más nítidamente en San Pablo en donde la unidad entre policía, ejército y paramilitares fue más notoria y la gente no es boba, la gente sabe entender ${ }^{33}$.

Ricardo menciona la tradición organizativa existente en la región, por lo que le pedimos hablar si esta había persistido después de las masacres y cómo la comunidad había reaccionado a la muerte de las personas, frente a lo cual emergieron relatos en torno a diversas prácticas de sociabilidad y formas de duelo que

32 Enzo Traverso, «Historiografia y memoria: interpretar el siglo XX». Aletheia, Vol. 1, n 2 (2011), http://www.aletheia.fahce.unlp.edu.ar/numeros/numero-2/no2-en-pdf/Traverso\%20 1-\%20Ok.pdf.

33 Ricardo, entrevistado. 
fueron desplegadas en ese momento en el plano local, así como la tramitación de acciones legales en pro de verdad y justicia, prácticas que hacen parte de los repertorios sociales y culturales con los que individuos y comunidades enfrentan contextos de violencia, y que deben ser recogidos por las políticas públicas.

La primera reacción es la más natural y la más humana jel miedo!, algo así como que las ovejas estaban juntas y llegó el lobo y todo mundo a correr, es decir se dispersan y después como que la gente toma conciencia y dice «no, volvamos a lo que nos ha hecho fuertes, a organizarnos», entonces ya empiezan a mostrar solidaridad con los dolientes, empiezan a acompañar los sepelios. Y los sepelios eran una forma de protestar y de decirle al otro: ustedes se equivocaron y pasean el féretro por la plaza y todo mundo lo llora, como diciéndole al grupo: «ustedes no tenían por qué matarlo». Entonces, es una forma de protesta muy fuerte... muy fuerte... Segundo, empiezan a hacer uso de la parte legal (llámese parte legal por ejemplo lo de derechos humanos), la gente empieza a hacer denuncias, a decir: ¡no!, esta persona no era lo que dicen, nosotros podemos dar cuenta porque lo conocíamos que no era guerrillero, ni auxiliador, ni colaborador de la guerrilla, y eso es una injusticia. Pero esto se hace cuando se siente el respaldo de una organización, porque solos es muy complicado, el temor sigue. Eso no niega que hubo desplazamiento, gente que tuvo que salir en aras de proteger su vida, pero sí hubo una protesta, una denuncia, un inconformismo, una resistencia de la gente ${ }^{34}$.

\section{Balances de la experiencia, transformaciones subjetivas y entornos sociales}

Hay algo curioso en la autobiografía. Es un relato efectuado por un narrador en el aquí y ahora sobre un protagonista que lleva su nombre y que existía en el allí y entonces, y la historia termina en el presente, cuando el protagonista se funde con el narrador ${ }^{35}$.

Como hemos visto a lo largo del artículo, la narrativa de Ricardo se centra en su experiencia como sujeto comprometido en una búsqueda de sí, que se articula con el compromiso social y los anclajes dados por el contexto socio-político en un país marcado por el conflicto armado y la violencia política

34 Ricardo, entrevistado.

35 Jerome Brunner, Actos de significado. Más allá de la revolución cognitiva (Madrid: Alianza Editorial, 1991), 119. 
en su historia reciente. En esta medida, en nuestros últimos encuentros buscamos activar recuerdos en torno a las afectaciones causadas por los hechos que nos narró en donde percibimos cómo lo individual y lo colectivo se anudan de modo indisoluble. Así, le invitamos a hablar sobre como él se veía a sí mismo en lo que nos había relatado y cómo elaboraba lo referente a aspectos éticos y políticos, en donde emergen una serie de elementos que el sujeto considera al someter a juicio las apreciaciones sobre lo político dentro de un contexto que torna confusos sus límites.

Lo político... <suspira> hay varios datos. Como les comentaba yo no he hecho una lectura de esto, estoy haciéndolo en caliente, sin guion, esto es jverraco! Lo político yo lo vería desde el ámbito de la acción humana de Arendt. La gente conocía su realidad, sabía identificar de qué lado se encontraba y percibía a todos estos actores como exógenos, sabía que tenían el poder de las armas pero que no podían dominarlos solo con ellas; la gente entendió que el poder de las armas era temporal y que el costo era la muerte, pero que no podían permanecer así, la gente sabía más de una forma de resistencia y darles la razón a ellos era exigirles el respeto a la vida y no abandonar su territorio.

Lo ético... < suspira $>$ Es más oscuro todavía, yo lo vería como una fidelidad a los principios. Y el principio de la gente que a mí más me impresionó fue la no violencia, no quiere decir que no haya habido un ataque a la alcaldía, como una vez lo hubo, pero la reacción no fue cojamos armas y saquémoslos, defendámonos!! En San Pablo la gente con el familiar muerto no reaccionó: «yo quiero venganza», sino JUSTICIA, esa es la cosa. Digo que lo ético lo veo más oscuro porque no es tan claro en las posiciones de la gente. La gente no se iba de frente porque se encontraba con las balas ipendeja no es la gente! entonces la gente decía: venga, organicémonos en torno a algo y ese algo lo defendemos, defendemos lo que nosotros somos ${ }^{36}$.

También le preguntamos qué podría decir de los cambios en su vida a partir de esas vivencias y cómo se posiciona ahora frente a este tipo de situaciones violentas, y de qué modo lleva su experiencia a su labor como docente. En el relato, al tiempo que valora estar vivo y la posibilidad de recomenzar, deja entrever

36 Ricardo, entrevistado. 
sus convicciones éticas y sus formas de entender, tal vez como lo reforzó de la comunidad de San Pablo, la no violencia como la actitud con la que el país, los educadores, los estudiantes, deberían enfrentar el conflicto político.

Cuando llego a Bogotá, con una maletica de ropa llego al terminal y digo <suspira> estoy vivo uff!! estoy vivo y ¿qué mierdas voy a hacer yo? Pero nunca hubo deseos de venganza, nunca... eso si te lo puedo decir... inunca! Y creo que eso lo aprendí de la gente, porque la gente no tomó las armas como retaliación y yo creo que debí aprender también eso, no sólo por la lógica o racionalismo kantiano... Lo que ha cambiado en mi vida es el escenario, lo que cambia son los actores, pero la honestidad no se negocia, ni la no violencia tampoco. Yo creo que es una mirada desde el humanismo, ¿sí?, yo me situó ahí... esa verdad o esa más que verdad... el término puede ser algo pretencioso... tener la verdad ... digamos que ese principio no ha cambiado... O sea yo sigo pensando que la violencia en este país no es el camino ${ }^{37}$.

Desde este mismo horizonte de sentido, se refiere a las clases que imparte hoy en día como profesor de filosofía a jóvenes entre 14 y 16 años, y los cambios que su experiencia le llevó a hacer como docente dejando entrever sus percepciones sobre los jóvenes, sobre el conflicto político y sobre el compromiso social, y sobre las implicaciones pedagógicas que deben ser asumidas por el profesor:

Creo que yo mentiría si digo que la experiencia del Magdalena Medio no me transformó, yo creo que me transformó incluso la forma, el sentido y la intencionalidad de enseñar filosofía. La historia de la filosofía yo la he relativizado, ahora no me interesa como un modelo de repetición de autores sino que se convierta en un pretexto para pensarnos la vida, ¿sí?, y que se convierta no sólo en un medio que nos ayude a tomar una actitud frente a la vida, clarificarla y al menos dejarse permear por otro tipo de discursos que no sean los hegemónicos, por ponerlo en términos nuestros... Creo que he podido como escarbar, como decantar qué cosas valen la pena de ser enseñadas, ¿sí?, a que cosas vale la pena apostarle.

Yo hablo mucho de lo político, del conflicto armado, en algunos cursos sobre todo cuando estamos estudiando las teorías del

37 Ricardo, entrevistado. 
estado, ¿sí?, en filosofía del estado es ineludible hablar del país y hacer una lectura de la realidad con los chicos, conversando con ellos se constata siempre la influencia de los medios de comunicación en la posición juvenil. Yo siempre les digo, recuerden, la realidad no es ni blanca ni negra, hay tonos de grises, admitan que dentro de esos polos hay posiciones y así como hay una derecha hay una izquierda, que a lo mejor la izquierda se haya equivocado... pero no podemos eliminarlos, hay otras posibilidades, no podemos eliminar al contendor, anular la diferencia... La constitución está montada sobre el respeto a la diferencia y no podemos ser contradictorios en lo que hacemos ${ }^{38}$.

Ricardo nos deja ver cómo sus trayectos, experiencias de vida, enunciadas a través de sus relatos, contienen la multiplicidad de relaciones que componen y recomponen el mundo social. En otras palabras, los fenómenos se encuentran contenidos en las subjetividades, sin embargo se expresan desde la singularidad, bajo un ángulo especial. Lo anterior dice de una temporalidad y espacialidad particular que es la expresión de la forma de vivir y experimentar los fenómenos sociales. En este sentido, la historia no es una narración rectilínea sino una miríada de tejidos, de encrucijadas que a cada momento ofrecen ramificaciones. Negar estos sinuosos caminos e interrelaciones es excluir a los individuos de su estar en la historia y su posibilidad de resignificación y creación de los fenómenos y lo social. Por lo anterior, se hace importante una investigación que conecte la experiencia individual y las biografías con el transcurso de los fenómenos, como una expresión de la comprensión de los sujetos en el tiempo-espacio de los acontecimientos históricos.

\section{Conclusiones}

El trabajo con relatos biográficos permite identificar las sinuosas relaciones entre la trama de la vida colectiva y la configuración subjetiva. A su vez, conceden reconocer los sentidos dados a una serie de acontecimientos, los que desde otras perspectivas serían tan solo eventos en sucesión que, si bien hablan sobre fenómenos dados en la historia de Colombia, pueden perder de vista sus afectaciones tanto en la esfera de

38 Ricardo, entrevistado. 
lo íntimo como en el tejido social. Los relatos evidencian cómo los fenómenos de violencia afectan a los sujetos pero también develan sus formas de resignificación en el momento en que elaboran lo vivido a través de la narración, proceso en el que intervienen las trayectorias individuales de los sujetos, los repertorios culturales que portan, así como el espacio en el que se les ha posibilitado para aludir a sus experiencias.

Sumadoalo expuesto, losrelatos biográficos, comounapuerta de entrada a la comprensión de los acontecimientos históricos, posibilitan pensar la manera en que se conectan la memoria individual, la memoria colectiva y la memoria histórica. Esta trama de relaciones evidencia la forma en que las subjetividades se dan en el marco de la simultaneidad y la contingencia. En este sentido, el análisis de la experiencia individual y colectiva coadyuva no solo a comprender las afectaciones en los individuos, sino los modos de ser de los sujetos en cada época, las figuras que los acontecimientos adquieren en lo situado, y al tiempo superar la idea de construcción histórica como la identificación de causas y consecuencias, para pensar los fenómenos desde miradas complejas, pues la experiencia no es solo de un individuo, sino de las formas en que se establecen relaciones en lo social.

El relato trabajado y la visibilización del sujeto que lo encarna también da cuenta de la influencia que las comunidades eclesiales de base (CEBs) han tenido en la configuración de activistas sociales en América Latina, las cuales han contribuido de manera general a modular sujetos que le apuestan a las soluciones pacíficas para enfrentar los acontecimientos de violencia política, cuyos repertorios deben ser retomados en el marco de sociedades que le apuestan al posconflicto.

Para que una sociedad pueda continuar con un presente vivible y con posibilidades de futuro plausibles se deben acometer acciones, que permitan reparar el tejido social causado por la guerra y el conflicto, así como los quiebres causados en las subjetividades, de ello depende en buena parte las posibilidades de establecer formas de convivencia en sociedades caracterizadas por el posconflicto. Desde esta 
óptica, los relatos biográficos se convierten, para el trabajo histórico, tanto en archivos, a los cuales se puede acudir para identificar y comprender fenómenos, como en testimonios que vislumbran las configuraciones culturales y políticas en las que se constituyen los sujetos.

Como nos menciona Estripeaut-Bourjac:

La intensidad con la cual las formas autobiográficas circulan actualmente en Colombia induce a establecer un nexo entre una situación, que se puede llamar de urgencia, y la práctica de la identidad. Más allá de todos los cuestionamientos metodológicos que esas formas plantean, pueden verse como salidas que se le ofrecen al "yo" para mantenerse como tal en un cotidiano desquiciado ${ }^{39}$.

El relato biográfico abordado en este artículo da cuenta de la experiencia vivida por sujetos que, como el caso del entrevistado, han mostrado su activismo y compromiso social dentro del contexto colombiano, marcado por la violencia política y el conflicto armado, sujetos que han colocado en riesgo su vida bajo el ideario de contribuir a forjar sociedades más justas y equitativas, cuyas memorias y repertorios sociales y culturales deben ser recogidos hoy en día para la comprensión de nuestro pasado y la construcción de horizontes de futuro que tomen distancia de la violencia armada como forma de acción dentro de la esfera política.

\section{Bibliografía}

Arfuch, Leonor. «El espacio teórico de la narrativa: un desafío ético y político». Utopía y praxis latinoamericana. Año $13, \mathrm{n}^{\circ} 42$, (2008): 131-140.

Asociación Campesina del Valle del río Cimitarra. «[Colombia] La masacre de San Pablo (Sur de Bolívar)». Kaos en la Red, Colombia, 6 de enero de 2013. Acceso el 21 de marzo de 2013, http://kaosenlared.net/america-latina/item/42850-colombiala-masacre-de-san-pablo-sur-de-bolivar-conmemoran-los-14a\%C3\%B1os-de-la-matanza.html.

39 Marie Estripeaut-Bourjac, Palabras de mujeres. Proyectos de vida y memoria colectiva (Bogotá: Siglo del Hombre, 2012), 23. 
Atehortúa Cruz, Adolfo León. Prólogo a Memoria y Formación. Configuraciones de la subjetividad en ecologías violentas, Martha C. Herrera, Piedad Ortega, José Gabriel Cristancho, Vladimir Olaya, Bogotá: Universidad Pedagógica Nacional, 2013.

Bidegaín, Ana María. «Las comunidades eclesiales de base (CEBs) en la formación del partido dos Trabalhadores (P.T.)». Historia Crítica, no 7, (1993): 92-109.

Blair Trujillo, Elsa. «Los testimonios o las narrativas de la(s) memoria(s)» Estudios Políticos, nº 32 (2008): 85-115.

Brunner Jerome. Actos de significado. Más allá de la revolución cognitiva. Madrid: Alianza Editorial, 1991.

Bustamante, Fabián. «La participación de las comunidades eclesiales de Base (cebs) en la regeneración del tejido social popular brasileño durante la dictadura militar 1964-1985» Revista Encrucijada Americana. Año 3, nº 1. Otoño-Invierno, (2009): 177-200.

Camarero, Daniel. «Las comunidades eclesiales de Base. Perspectiva latinoamericana». Acceso el 6 de noviembre de 2016, http:// mercaba.org/Pastoral/C/comunidades_eclesiales_base_ LA.htm.

Claux, Carriquiry, Inés. La búsqueda. Del convento a la revolución armada. Testimonio de Leonor Esguerra. Buenos Aires: Aguilar, 2011.

Comisión Intereclesial de Justicia y Paz. «10 años de Impunidad de la Masacre en Barrancabermeja». Acceso el 13 de julio de 2017, http://justiciaypazcolombia.com/10-anos-de-Impunidadde-la-Masacre.

Comisión Intereclesial de Justicia y Paz. «Diez años de impunidad de la masacre en Barrancabermeja». Acceso el 13 de julio de 2017, http://justiciaypazcolombia.com/10-anos-de-Impunidadde-la-Masacre.

Cornejo, Marcela, Mendoza, Francisca, Rojas, Rodrigo. «La Investigación con Relatos de Vida. Pistas y Opciones del 
Diseño Metodológico» Psykhe, Vol.17, nº 1 (2008): 29-39. DOI: https://doi.org/10.4067/S0718-22282008000100004

Cruz Manuel. «Tiempo de narratividad. El sujeto, entre la memoria y el proyecto», Análisis, no 25 (2000): 23-40.

Delory-Momberger, Christine. «Lo Biográfico: una categoría antropológica». En Biografía y formación. Narración de sí e Investigación, compilado por Martha Sarria Materón, 61-78. Cali: Universidad del Valle, 2007.

Estripeaut-Bourjac, Marie, Palabras de mujeres. Proyectos de vida y memoria colectiva. Bogotá: Siglo del Hombre, 2012.

Genette, Gerard. Palimpsestos. La literatura en segundo grado. Madrid: Taurus, 1989.

Halbwachs, Maurice. La memoria colectiva. Zaragoza: Prensas Universitarias de Zaragoza, 2004.

López De La Roche, Fabio. Izquierda y Cultura Política ¿Oposición alternativa? Santa Fe de Bogotá: CINEP, 1994.

Langer, Lawrence. Holocaust Testimonies. The ruins of memory. New Haven and London: University Press, 1991.

Mallimaci, Fortunato, y Verónica Giménez Béliveau, «Historias de vida y método biográfico» En Estrategias de Investigación Cualitativa, coordinado por Irene Vasilachis, 175-212. Barcelona: Gedisa, 2006 .

Pécaut, Daniel. Guerra contra la sociedad. Bogotá: Planeta, 2001.

Pollak, Michel. Memoria, olvido, silencio. La producción social de identidades frente a situaciones límite. La Plata: Ediciones al Margen, 2006.

Pujadas, Joan J. «El método biográfico y los géneros de la memoria» Revista de Antropología Social, nº 9 (2000): 127-158.

Sánchez, Gonzalo. Guerras, memoria e historia. Medellín: La Carreta, 2006. 
Traverso, Enzo. «Historiografía y memoria: interpretar el siglo XX». Aletheia, Vol. 1, no 2 (2011). http://www.aletheia.fahce.unlp.edu. ar/numeros/numero-2/no2-en-pdf/Traverso\%201-\%20Ok.pdf.

Uribe, María Teresa. «El republicanismo patriótico y el ciudadano armado» Estudios Políticos, n ${ }^{\circ}$ 24. Medellín, Instituto de Estudios Políticos, enero - junio (2004): 75-92.

«La masacre de Barranca en las cortes internacionales» Verdad Abierta, Bogotá, 17 de marzo de 2009, Acceso el 15 de mayo de 2017. http://www.verdadabierta.com/index.php?option=com content\&id $=2277$.

«Masacres. La ofensiva paramilitar» Verdad Abierta, Bogotá, 2 de septiembre de 2008. Acceso el 17 septiembre de 2017, http:// www.verdadabierta.com/nunca-mas/masacres/202-masacresel-modelo-colombiano-impuesto-por-los-paramilitares.

\section{Citar este artículo:}

Herrera Martha Cecilia y Olaya Vladimir. «Violencia política y relatos desde la dimensión subjetiva». Historia Y MEMORIA, n 18 (2019) :49-76. DOI: https://doi.org/10.19053/20275137. $\mathrm{n}^{\circ} 18.2019 .7356$ 